\title{
6
}

\section{The Theory of Rights and the Practice of Abortion}

Is there a convincing argument for a right to abortion on demand? A variety of particular forms of such a right are now legally established in this and a large number of other legal systems, and it is known that these rights have been successfully exercised millions of times. Yet defenders of such a right are not in agreement as to the patterns of reasoning that best support it, and a large number of people continue to believe that abortion itself, and certainly a right to abortion on demand, are utterly indefensible. I hope to contribute to the discussion of this difficult matter by drawing explicitly on aspects of existing theory concerning rights. I will try to show that explicit attention to the idea that there should be a right to abortion on demand serves to clarify controversy over abortion and helps to produce a strong argument in favor of what has become (in an astonishingly short period of time given the centuries of opposition to it) accepted legal and moral practice over much of the globe.

It must be stressed at once that the question "Should there be a right to abortion on demand?" is not equivalent to the question of whether abortion is (ever) morally, legally, or otherwise justified or defensible. True, if abortion could not be justified at all, there could hardly be a justified right to it. But it is possible that abortion could sometimes be justifiable and yet that there would be no adequate justification for according or establishing any rights to have abortions. Abortions might be permitted under certain circumstances but in every case the decision for or against them would be made by some authority. (It could even be the case that abortions, were mandatory; which would imply that there was a duty to have one 
but no right to do so.) Rights are distinctive moral and/or jural entities, and having and exercising, protecting and respecting, violating and infringing on them are distinctive modes of action. It is impossible to derive a sufficient justification for any particular right from the distinctive characteristics of rights as such, but justifications for all particular rights are, tautologically but not trivially, justifications for rights and not something else. Hence such justifications must take the distinguishing characteristics of rights into account.

\section{What Is a Right?}

There are a number of distinct types of rights that will have to be distinguished if we are to make headway with our question about the right to an abortion on demand. There are nevertheless certain generalizations that hold across the major subtypes, and we will begin by discussing them.

We can think of the rights we actually have (as opposed to those that are merely proposed or that we may think we ought to have) as warrants for actions. These warrants are supplied by rules that are established in some society, group, or association. Once established the rules themselves warrant the holders ( $A$ 's) of the rights they create in taking a certain class or type of action $(X)$ and they place other persons ( $B$ 's), who can be expected to object to $A$ 's doing $X$, under various kinds of restrictions, prohibitions, or requirements in respect to $A$ 's doing $X$. When $A$ sets out to do $X$ and $B$ comes forward to object, $A$ can conclusively establish a kind of propriety for her doing $X$, and a kind of inapplicability for $B$ 's objection, by producing the constitutional provision, statute, court decision, feature of the moral code, and so forth that constitutes the warrant for her claimed right to do $X$. Such warrants hold against-that is, serve to defeat-a more or less clearly specified range of the known or anticipated objections to $A$ 's doing $X$. Thus to have a right to do $X$ in a particular jurisdiction, community, or group is to have a distinctive degree of assurance, in advance as well as during and after the fact of acting, that doing $X$ will be held to be proper by some criterion possessed of authoritative standing in that jurisdiction or society. Doing $X$ will be held to be correct or blameless despite the fact that members of the society vigorously object to it. 


\section{Toward a Liberalism}

Two features of this account of rights deserve further emphasis. First, when a society or group establishes a right it in effect adopts an official or collective or authoritative position concerning a more or less clearly identified class of actions and objections to that action. It commits itself, in advance of specific instances of the action qua exercises of the right (and hence in advance of knowing the consequences of particular instances of the exercise of the right), to the position that the class of actions will be permitted (and at least to that extent encouraged). The unfolding of experience may convince that this commitment is mistaken and may lead to alteration or repeal of the rule that established the right. But until such time as the rule has been changed, the action will be entitled to protection whenever proposed or taken by a holder of the right. Such commitments, moreover, are all but invariably made in the awareness that the actual exercise of the right will commonly be controversial, that there will be persons who strongly object to $A$ 's doing $X$. If it could be expected that $A$ 's doing $X$ would be universally welcomed or at least accepted, there would be no point to establishing a right to do $X$.

The second feature that deserves emphasis is implicit in the first. The commitment just described is in effect a commitment to accept and to protect the decisions of right holders to do $X$ or not. With rare exceptions that are irrelevant here, to have a right to do $X$ is to be at liberty to do $X$ or not as one sees fit. If $A$ decides that it will be to her advantage to do $X$, the fact that there is an established right to do $X$ itself warrants her in proceeding to do it. If she chooses to reveal her reasons for doing $X$ and others find them objectionable or even repugnant, they may think badly of her as a person and she may suffer some ill consequences as a result. But given that she has a legal right to do $X$, others cannot properly hold that her doing $X$ was, is, or would be illegal; given that she has a moral right, others cannot hold that it was, is, or would be immoral. The practice of according rights is one of the, probably the, single most dramatic respect in which societies accord autonomy of action to individual agents.

\section{Types of Rights}

The last sentence will require elaboration when I reach the question of the justification for including the practice of rights among 
the arrangements and institutions that structure our legal and moral lives. It will also prove to be a crucial consideration in my proposed justification for a right to abortion on demand. But before taking up these matters I must pause to note some significant distinctions among types of rights, distinctions that concern the particulars of the warrants supplied by various rights. Because the distinctions in question are familiar and largely uncontroversial, and because I can barely touch the interesting theoretical questions that arise concerning them, this part of our discussion will be brief.

The all but canonical work here is by Wesley N. Hohfeld. ${ }^{1}$ Responding primarily to legal materials (statutes, court opinions, legal commentaries), Hohfeld developed distinctions among four recurrent uses of "a right" and "rights." He drew the distinctions in terms of what he called the "correlates" and the "opposites" of each of the uses. The correlate is the jural attribute that attaches to some $B$ by virtue of $A$ 's having a right of a particular type. The opposite applies to $A$ herself and is what the term says, namely, the opposite of having the right that $A$ actually has. (On examination the notion of the opposite of a right commonly proves to be elusive.) In schematic form the four types are as follows:

$\begin{array}{lll}\text { Type of right } & \text { Correlate } & \text { Opposite } \\ \text { I. liberty } & \text { no-right } & \text { duty } \\ \text { 2. right strict sense } & \text { duty } & \text { no-right } \\ \text { 3. power } & \text { liability } & \text { disability } \\ \text { 4. immunity } & \text { disability } & \text { liability }\end{array}$

Probably the most familiar of these types is the second, rights in the strict sense. If $B$ validly contracts to pay $A \$ 400$ per month for the use of $A$ 's apartment, $A$ thereby acquires a right in the strict sense to that payment and $B$ a correlative duty to make the payment. The important point is that there is no such thing as a right of this type without an identifiable $B$ or $B$ 's with a specified obligation in respect to that right. In the language used above, the combination of the rules concerning contracts and the fact that some $B$ has entered into a valid contract with some $A$ warrants $A$ in demanding that $B$ pay and (assuming no defeating conditions intervene) puts $B$ under a definite obligation to meet that demand.

Both the difficulty and much of the interest of the first type, rights

1 See Wesley N. Hohfeld, Fundamental Legal Conceptions, ed. W. W. Cook (New Haven: Yale University Press, 1919). 


\section{Toward a Liberalism}

in the sense of liberties, lie in the correlate that Hohfeld dubbed a "no-right." As the category name indicates, if $A$ has a right to $X$ in this sense she has a liberty, is at liberty, to do $X$. But what exactly does this imply for other persons? Presumably the $B$ 's have a duty to respect the right. But of what does respecting the right consist? My own interpretation, which I have elaborated elsewhere ${ }^{2}$ is that $B$ 's no-right merely(!) means that she must not contend that it was, is, or would be wrong for $A$ to do $X$. If the liberty is a legal one, $B$ must not contend that $A$ 's doing $X$ is illegal; if the $X$ is a moral liberty, $B$ cannot properly contend that $A$ 's doing $X$ is morally wrong or blameworthy. Unlike rights in the strict sense, however, $A$ 's liberties do not warrant her in demanding, and $B$ 's no-rights do not obligate her to perform, any affirmative action to aid or facilitate $A$ 's doing $X$. Indeed the combination of $A$ 's liberty and $B$ 's no-right does not itself prohibit $B$ from acting in ways that may, as a practical matter, make it difficult or impossible for $A$ to succeed in doing $X$. To take a familiar example, if $A$ 's right to freedom of speech under the United States Constitution is a liberty, $B$ (the Congress, a police officer, an ordinary citizen.) may not contend (or act on the contention) that it would be illegal for $A$ to exercise that right. But $B$ need not supply $A$ with a soapbox, a public address system, or time on national television. Indeed $A$ 's liberty does not itself prohibit $B$ from beating a bongo drum so that $A$ 's speech cannot be heard. ${ }^{3}$

\section{How Can Rights Be Justified? \\ The Liberal Principle}

The bearing of the foregoing on the question of a right to abortion on demand is not far to seek. To accord a right of any sort to

\footnotetext{
2See Richard E. Flathman, The Practice of Rights (New York: Cambridge University Press, 1976). A number of the questions taken up in this chapter are discussed in greater detail in this work.

${ }^{3}$ Rights in the sense of powers and immunities have less relevance to issues about abortion, and I will simply give an example of each to make the distinctions somewhat clearer than they are in the above schema. A standard example of a right in the sense of a power is the legal capacity to make a will. It would be impossible to make a will apart from the constitutive rules of will making. But $A$ 's power to make a will imposes no obligations on $B$. What it does is make $B$ liable to become a beneficiary of $A$ 's will should $A$ choose to exercise her power to write one. When $A$ actually makes a will that includes $B$, rights in the strict sense are likely to result. A
} 
abortion on demand would be (is) to provide all those who have that right and who decide they want an abortion with a warrant for having one, a warrant that is established as conclusive against some specified range of objections against the desire and its satisfaction. If the right is a legal right in the sense of a liberty, according it bars all other persons (in the jurisdiction) from contending that having an abortion (under the conditions included in the definition of the right) is or would be illegal; if a moral liberty, it bars all other persons (in the moral community) from contending that having an abortion (under the conditions included in the definition of the right) is morally wrong or blameworthy. If the right is a legal or a moral right in the strict sense, it would be established that the desire to have, and having, an abortion is not only innocent but imposes some further obligations (for example, to perform the abortion if one is a qualified physician) on assignable $B$ 's. To accord a right to abortion on demand, in other words, is not merely to say that there is a reasonable case for abortion, that fair consideration will be given to allowing abortions under certain circumstances, or that others will respond tolerantly, charitably, or sympathetically to persons who wish to have or have had abortions. Rather, it is to put the legal or moral authority of the society or community on the side of those who want abortions and against the objections of those who oppose them.

Quite clearly, it would be impossible to justify according any species of right to abortion without detailed consideration of the characteristics and consequences of abortion itself, of the particular conditions under which the right would obtain, of the type of right under consideration, and (in the case of rights in the strict sense) of the specifics of the obligations that would correlate with the right. As with all rights without exception, sufficient justifications and disjustifications are impossible apart from the particulars of the right in question.

standard example of an immunity is represented by the Fifth Amendment provision prohibiting compulsory self-incrimination in certain classes of cases. Ordinarily the prosecutor, judge, congressional investigating committee, and the like have authority to require an accused person or witness to testify, and the latter are under a liability to be questioned and have an obligation to respond when questioned. But $A$ 's immunity qualifies that authority and its correlative liabilities and resultant obligations and puts the prosecutor, judge, congressional investigating committee under a disability to ask certain classes of questions. 


\section{Toward a Liberalism}

It nevertheless remains the case that all rights are rights; that it is impossible to accord a right to a particular $X$ without according a right. And because a right is a something, not an anything whatever, because rights are characterized by a more or less distinct and identifiable family of characteristics (albeit it would be impossible to state the necessary and sufficient conditions of something counting as a right), there are considerations of a more general nature which bear on the question of whether there should be any rights at all and on the question of whether, given that we know something about a particular $X$, there should be a right to that $X$.

Among the most prominent of the features characteristic of rights is the extent to which they protect and encourage freedom of action on the part of the individuals (or other agents) who hold them. The most obvious respect in which this is true is the one I have been discussing: in ways that vary according to the right in question, $A$ 's desire to act is protected against objections and other forms of resistance thrown up by persons who believe that they, others, or some thing or state of affairs will be disadvantaged or harmed by $A$ 's proposed action. This deserves to be regarded as a feature of the logic of the notion of rights. If no restrictions of any kind are placed on any $B$ 's, we simply are not dealing with a right.

This characteristic of the logic of a right is surrounded or accompanied by a number of others, one of which might be called the asymmetry between the positions of $A$ and $B$. It is ordinarily for $A$ to decide whether to exercise her rights or not. Whereas in most cases it is clearly wrong for $B$ to fail to discharge her obligations vis-à-vis $A$ 's right, the notion that it is wrong for $A$ not to exercise her rights is not well established. If a second party criticizes $A$ for not exercising rights that $A$ clearly has, $A$ is usually justified in telling that party to mind her own business. A cannot unilaterally determine what rights she has, but her autonomy in deciding what to do with her rights is very great.

A second such feature concerns the rhetoric characteristic of rights discourse, especially the rhetorical style characteristic of the $A$ 's. It is not only common but generally thought unexceptionable for $A$ 's to claim, maintain, assert, demand, and insist on their rights. And it is seldom taken amiss, often applauded, if they do so insistently, forcefully, staunchly, boldly, and even zealously. A right is something to which one is entitled, something one can unabashedly and unapologetically assert against all challenges and challengers. 
How can a practice with these characteristics be justified? What assumptions are being accepted in a society that not only sustains such a practice but gives it, as this society has done, an honored place among its institutions and arrangements? It is worth noting in this context that the practice of rights is by no means without its critics. There have been and are societies and cultures that find the self-assertive individualism characteristic of the practice of rights deeply objectionable. Indeed there is a persistent minority in this culture that reacts negatively to the very idea of rights. In most cases this view is associated with yearning for a greater degree of community, fraternity, and similar values in human relations. Persons who espouse it seek fellowship, integration, and cooperation; deep, intense, and intimate ties. And they find the practice of rights antithetical to these values. Rights are said to disaggregate and to fragment. They generate selfishness and competition rather than friendship, love, and a willingness to sacrifice for others and for the community.

A society or culture that sustains and celebrates individual rights has not necessarily rejected all of the values associated with concepts such as community. Its members may believe that there is an important, even a vital place for love, friendship, and fellowship; they may want to sustain relationships to which rights and their exercise are indeed inappropriate. But it is clear that a society or culture will not value the practice of rights as we know it unless it has a strong commitment to some kind of individualism; unless the preponderance of its members believe that free, autonomous individual action is at least one of the chief among their values, a value that social, political, and moral institutions and arrangements ought to honor and to serve.

It will be convenient to give this commitment or value a more explicit formulation and to provide it with a name. The name I propose is "the liberal principle" (LP) and the formula I will employ is as follows:

It is a prima facie good for individual persons to have and to be in a position to act on and to satisfy interests and desires, objectives, and purposes.

Although it is impossible to derive or defend this principle in anything like adequate detail here, three comments concerning it cannot be avoided. 
First, I take it to be a part of our moral (as opposed to our merely genetic or biological) concept of a human being that all human beings in the moral sense (hereafter human persons or simply persons $)^{4}$ do have interests and desires, purposes and objectives, and are capable of acting on and pursuing them. This feature of the concept shows up in many ways, one of the more dramatic of which is the very special manner in which we expect one another to relate to persons who for some reason have failed fully to develop these characteristics or who have partially lost them. Consider the vastly greater care that is owed to such persons; the concern, solicitude, active helpfulness, and so forth that is expected in respect to them. By contrast, interactions among persons who suffer no such disabilities may appear to be almost reckless in the ways in which they presume that others can, as we sometimes say, "take care of themselves." (Which is part of the reason that persons with partial disabilities are, rightly, sensitive about inappropriate forms of "solicitude" which assume that the partially disabled person cannot "take care of herself" in respects in which, in fact, she is perfectly well able to do so. $)^{5}$ In short, the interested, purposive character of

4There is of course controversy concerning how this distinction should be drawn and what inferences can be made from and concerning it. I will be elaborating and defending my use of the distinction below. But that there is and must be some such distinction could hardly be controverted. For a vigorous defense of the distinction, see Michael Tooley, "Abortion and Infanticide," in The Rights and Wrongs of Abortion, ed. Marshall Cohen, Thomas Nagel, and Thomas Scanlon (Princeton: Princeton University Press, 1974).

5I will take the occasion provided by this turn in the discussion to remark on a point concerning abortion itself. It is commonly suggested that the pro-abortion position implies or otherwise invites insensitivity and worse toward life forms that, as with the fetus, lack characteristics of full human personhood or personality. I deal with aspects of this argument below. But it is worth emphasizing the point made in the text above, namely, that our duties to human persons who lack a part of the usual complement of characteristics are commonly and rightly thought to be much stronger, much more demanding, than those owed to persons with no disabilities. The judgment that a member of some class departs in some way from the usual characteristics of the class to which she or it belongs cannot itself settle the question of how she or it ought to be treated.

I permit myself one further aside of a somewhat polemical nature. I am inclined to think that the attitude of anti-abortionists toward women commonly presents an extreme case of the kind of recklessness toward normal human persons mentioned above. It is admitted that women are deeply affected by pregnancy, childbirth, and child rearing, and so forth. But it is assumed that "they can take care of themselves" in these regards, that is, that they do not require the help provided by such things as rights to abortion. This attitude might be acceptable, might even be a kind of 
human persons is ordinarily presupposed or taken for granted. And where this presumption must be qualified in respect to the ability of an individual to act on her interests and desires, other persons are expected to give special attention to fostering and serving them.

These same considerations - and this is the second comment-go some distance toward supporting what is of course the chief moral thrust of LP, namely, that it is prima facie a good thing for persons to be able not just to have and to act on but to satisfy their interests and desires, achieve their purposes and objectives. A related consideration that offers further support concerns what can be called the transitive character of interests, desires, and so forth. All interests and desires are in or for some object or state of affairs, all purposes and objectives make essential reference to a condition or outcome that it is the person's purpose or objective to achieve. Hence to say (I) that persons have interests and desires, objectives and purposes, and (2) that this is a good thing is surely to imply (3) that it is, at least prima facie, a good thing to satisfy the interests and desires and achieve the objectives and purposes. To state (I) and (2) but to deny (3), although not formally a contradiction, is at least to write a recipe for intolerable frustration.

My third comment on LP will bring us closer to its bearing on the justification for rights. As is indicated by the qualifier "prima facie," the principle is not itself a sufficient justification for any action. If accepted, the principle establishes a presumption that individuals ought not to be criticized for or otherwise prevented from having, acting on, and satisfying interests and desires, objectives and purposes. All criticisms, prohibitions, and so forth must be justified in the light of the fact that they prevent or qualify the achievement of a prima facie good. But the presumption that the principle establishes is always subject to defeat. In respect to any action whatever (save the action of denying the principle itself) it may be possible to justify a criticism, a prohibition, or a constraint.

For this reason alone LP will not itself sufficiently justify any right and hence will not sufficiently justify any instance of the practice of rights. Any right, and hence the practice of rights in any instantiation, involves additions to the protection that LP provides for individual actions. It adds the notion that there are some actions

compliment, if they were in fact allowed to takecare of themselves, that is, to handle sexual relations, pregnancy, and the like in their own way(s). 


\section{Toward a Liberalism}

that are not simply prima facie good but are conclusively justified against some more or less definite range of objections. And rights in the strict sense add the further protection accorded by the particular obligations they assign to the $B$ 's. These additions require defense. They require defense, among other reasons, because they involve restrictions on the very good that LP celebrates. This is most obvious in respect to rights in the strict sense because the obligations that such rights entail serve to prevent the $B$ 's from acting on and satisfying those interests, desires, and so forth that prompt them to want to interfere with $A$ 's doing $X$. Thus adherents of LP have reason to be suspicious of the practice of rights and of all particular rights.

LP nevertheless provides a plausible foundation for the practice of rights. This is because the principle celebrates that very individualism and freedom of individual action for which rights provide further and more conclusive kinds of protection. (That is, given that there will be rules, laws, and restricting institutions and practices of some sort, the practice of rights celebrates such individualism more explicitly and directly than the other rules and practices with which we are familiar.) A society strongly committed to LP, it is true, will almost certainly be in need of fewer rights than one with a weak commitment to it. This is because its members will already have committed themselves to respect for the kind of individualism that rights protect. But it will also be well prepared for the practice of rights. If it finds that certain modes of individual action are particularly important and yet especially liable to interferences and objections, acceptance of the idea of according those actions the special protection that rights afford will come easily to it.

\section{Can a Legal Right (Liberty) to Abortion on Demand be Justified?}

Arguments for Such a Right: LP Applied

Manifestly, a very large number of women have had, now have, and can confidently be expected to develop an interest in or desire for an abortion; manifestly, at some point or points in their lives a great many women make it their objective or purpose to have an abortion. Thus if we approach the issue of abortion from the per- 
spective given by a practice of rights thought of as supported by LP, it will follow immediately that being able to have an abortion when one is in fact desired is a prima facie good, the denial of which requires explicit and substantial justification. Because it is also known that there is likely to be opposition to having an abortion when desired, it is also at least initially plausible to think that there ought to be some species of right to have one.

The contrast between this perspective on the matter and what might be called the traditional approach to it is of course very great. The traditional approach (to abortion and to a great many other moral issues) is to assume that the individual's interests, desires, and so forth are suspect, are probably guilty in some way, and to search revelation, natural law or right, tradition, the needs of the moral or legal community, or some other body of transcendent truth for (the expected) evidence that satisfying, acting on, or even having the particular interests and desires in question is indeed blameworthy and is therefore to be prohibited, prevented, punished, exorcised. No one who has read the by now voluminous anti-abortion literature can fail to be impressed by this among its characteristics. It is increasingly common for anti-abortion writers to concede that back-alley abortions are unpleasant and regrettable, that unwanted children enter life under great disadvantages, perhaps that the burgeoning world population threatens all life with catastrophe. It is rare indeed to encounter the view that the interests and desires, objectives and purposes, that (after all) make up so much of the lives of human persons are themselves deserving of immense respect and support.

Given this circumstance, little or nothing of a practical sort could be accomplished simply by stating LP in abstract formulation and pointing in a general way to its obvious applications to the question of abortion. Even if we do not regard interests and desires as guilty, we are all too wont to denigrate them with adjectives such as mere; to think of them as fleeting, evanescent, and insignificant. Purposes and objectives that are "merely individual" are also thought to be eligible for this treatment. We have been taught to think that what matters in life is virtue and duty, the sacrifice of individual interests and objectives to high moral principles and transcendent truths, the subordination of the individual to the community, the nation, the church. Thus even so erudite and incisive a student of the abortion 


\section{Toward a Liberalism}

issue as Professor Noonan has argued that the pro-abortion movement has taken much of its strength from "a trend to reject all codes of morality" and "a desire to be free of a code of morality."6

But there is nothing "mere," "insignificant," "unprincipled," or a-, non-, or immoral about respect for the interests and desires, objectives and purposes of individual human persons. Nor is there anything abstract about the significance of LP in its application to the question of abortion. Admittedly some interests and purposes are more substantial, more lasting, more important than others. One of the advantages of approaching questions about rights from the perspective of $L P$ is that the latter allows of a ranking of interests and desires and hence provides logical space for the judgment that some, but by no means all, of them deserve the special protections afforded by establishing rights to act on them. But it could hardly be suggested, especially by anti-abortionists, that a woman's interest in having an abortion is trivial or insignificant. Having elevated childbearing and rearing to the status of acts of the greatest possible sanctity, having treated motherhood and its duties as sublime and life-pervasive, anti-abortionists can hardly turn about and dismiss a woman's interests and desires in respect to them as transient and insubstantial.

Accordingly, I will resist the temptation to elaborate on the significance of the more obvious of the interests (for example, those that concern pregnancy and childbirth themselves) which a right to abortion on demand would protect. But there is one aspect of this matter, one that connects directly with the theory of rights, which requires discussion.

The value, to its possessor, of a right is not restricted to the protections it affords at the moment or moments of its exercise (in the sense of the actual doing of the protected act-in this case the actual having of the abortion). Its value projects back and out from that moment to the whole skein of thoughts and actions that precede it in more or less connected ways, and it projects forward into the continuing life of the actor after that moment. I personally have had relatively few occasions explicitly to assert and exercise my right to freedom of speech against specific challenges and challengers. But the knowledge that I have that right is a recurrent

${ }^{6}$ John T. Noonan, Jr., ed., The Morality of Abortion (Cambridge: Harvard University Press, 1970), p. xv. 
influence on my activities. I think thoughts, make plans, attend to events in my society, consider modes of action, and so forth in ways that would be impossible or that would be done under very different circumstances if I were living in Chile, Uganda, or the Soviet Union. And my life following any exercise of the right has, if anything, been yet more markedly different than it would have been in the absence of the right.

Consider in this perspective the position of women in societies that have not established a right to abortion on demand. Consider in particular their position in respect to sexual relationships (and the entire constellation of potentially joyful experiences that radiate around such relationships) during those stretches of their lives in which they do not want to undertake the bearing and rearing of a child. It is no exaggeration to say that these relationships, which can be so beautiful, so sublime, so life-enriching and enhancing, are commonly sources of anxiety, sometimes of fear, sometimes of something close to terror. And for good reason. Assume "the worst" occurs and the woman becomes pregnant. If she is married and chooses to carry the fetus to term and to raise the child, her plans for her own life will certainly be significantly affected and may have to be entirely given up. If she seeks permission to have an abortion, she faces official interrogations, hearings, the making of judgments-in short, gross intrusions by strangers into the most intimate aspects of her life. For much of human history her alternative has been the debilitating and very likely dangerous ministrations of the illegal abortionist. And in either case, especially if she has the abortion, she must face the guilt and the shame that societies insistently impose on women who have not taken "due care." If she is unmarried, the entire experience is in all likelihood very much the worse, and its adverse effects might well continue through the remainder of her life.

Under these circumstances, which have been relieved but by no means eliminated owing to improvements in and the easy availability of contraceptive devices (relieved, that is, for those who have not been taught to feel ashamed of using such devices), the absence of a legal right (liberty) to abortion on demand projects its destructive consequences backward and forward in time (from the moment at which the right would actually be exercised) and inflicts those consequences on much of the woman's life.

The contrast between such a circumstance and one in which a 


\section{Toward a Liberalism}

right to abortion has been established could hardly be sharper. In the latter case, women can enter into that whole array of life experiences that radiate out from sexual relations secure in the knowledge that control of the effects of those experiences on their lives is largely in their hands; secure also in the knowledge that they can exercise that control in dignity free of clumsy and unwelcome intrusions. I would not deny that it is possible to enter imaginatively and sympathetically into the differences between these two situations and nevertheless conclude against a legal right to abortion on demand. I do not see how it is possible for anyone who appreciates the enormous differences between them to deny that there is a powerful case for such a right.

\section{Arguments Against a Legal Right (Liberty) to Abortion}

There are of course a number of additional arguments that are commonly advanced by proponents of abortion on demand. Many of these concern social consequences-the ill consequences of prohibiting abortions and the good consequences of a right to it. Although cogent and indeed persuasive in many instances, the use of these arguments in support of an individual right would introduce complexities (having to do with the so-called utilitarianism of rights) which cannot be dealt with here. ${ }^{7}$ Accordingly, and because I believe that the foregoing arguments constitute a strong case for a legal right (liberty) to abortion on demand, I leave the other arguments aside and turn to the case against such a right.

That there is such a case, and that it merits a serious response, has been implicitly conceded in the foregoing discussion. If opposition to a legal right to abortion on demand were without creditable foundations, if it were based entirely on prejudice, misinformation, manifestly faulty reasoning, and the like, mounting a detailed argument for such a right would by now have been shown to be an exercise in futility if not irrelevance. But this is manifestly not the case. There are substantial arguments against a legal right to abortion on demand and we will have to concede to them on some points.

${ }^{7}$ The most compelling among the additional arguments, and those that introduce the fewest complexities, concern the ways in which respect for the interests and desires, objectives and purposes, of women carries over to respect for the interests of other persons involved in or affected by the abortion decision. 
Arguments Grounded in Characteristics of the Fetus as Such (as Opposed to the Potential That the Fetus Carries)

\section{The Fetus as Animate}

The least complicated of the arguments against abortion are based on principles such as the "sanctity of life" or "reverence for life" (as, for example, in the well-known formulations of St. JohnStevas and Albert Schweitzer). These principles require that the life of all animate, organic things be protected and even revered; that it never be intentionally or perhaps even knowingly destroyed if it is at all possible to avoid doing so. Given that from conception, certainly from implantation, the (embryo-cum-) fetus is undoubtedly animate, it follows that abortion, which is the knowing, in most if not all cases the intentional, destruction of the life of the fetus can be justified, if at all, only in cases in which it is the only alternative to the knowing, perhaps the intentional, destruction of some other living thing. Traditionally, this has been taken to mean that abortion is justified only if refusing it will cause the death of the mother, perhaps even constitute the intentional killing of the mother. ${ }^{8}$ And because advances in medical science have all but eliminated the possibility that such dilemmas will in fact present themselves, abortion is virtually always wrong.

There is very little that can be said for this argument. As noble as the sanctity of life principle may at first sight appear, accepting and acting consistently on it would, of certainty, lead to horrendous and utterly indefensible results. I will give but one of the many examples that not only support but require this judgment. In preparing for most medical procedures, doctors and nurses use antiseptics that are known and intended to destroy the lives of countless animate things. It could not be said that doing so is indispensable to preserving other lives, particularly not the life of the patient. Countless patients survived medical procedures very nicely before antiseptics and indeed germs were discovered. More to the point here, given the availability of antiseptics, antiobiotics, and other such medications,

8The distinction between knowing and intentional destruction of the fetus is at the basis of what is commonly called the doctrine of the double effect. I do not find the distinction or the doctrine helpful in respect to questions about abortion, but I cannot deal with the matter here. For a sensitive and helpful discussion, see esp. Philippa Foot, "The Problem of Abortion and the Doctrine of Double Effect," Oxford Review, no. 5 (1967), pp. 5 ff. 


\section{Toward a Liberalism}

we could now postpone their use until such time as definite evidence of infection presented itself. Since infection would very often not develop, such a practice would save the lives of untold numbers of living things at minimal if any risk to patients.

But such a procedure would be unthinkable. Let one human person die or even suffer from it and its outrageous character would be condemned by everyone who heard of it. We do not treat all animate things as of equal value. Avoiding the slightest risk to some creatures-say, sentient creatures-justifies the destruction of millions of animate but insentient ones. The most generous thing that could be said for the proposal to do otherwise is that it would reflect a truly wild and irrational form of sentimentality. To pretend that we do in fact or would ever take such a proposal seriously would be the sheerest hypocrisy. ${ }^{9}$

\section{The Fetus as Sentient}

The argument from the merely animate character of the fetus, then, is no argument at all. But the fetus as such is not merely animate; from a short time after implantation it begins to show clear signs of sentience or what is sometimes called simple (as opposed to reflexive or self-) consciousness. These signs multiply rapidly in the early stages of its development and are undeniable through much of its existence. Thus with the possible exception of its very earliest stages the fetus as such falls under the protections, whatever they are, of any principles that hold for sentient life, not just those that protect life itself.

There is at least one principle that applies to all sentient but no

9On this point, see Werner J. Pluhar, "Abortion and Simple Consciousness," Journal of Philosophy 7 I (1974): I65. "As sentience . . . grows dimmer and dimmer as we descend toward ever simpler organisms, the prima facie wrongness of destroying an organism inevitably decreases in proportion, ultimately to a degree of negligibility where it becomes in practice more misleading to affirm than to deny that there remains a residual prima facie wrongness at all, since it is standardly overridden by just about any countervailing consideration, moral or other."

It does not follow that no consideration whatever is owed to life as such. The wanton, pointless destruction of any living thing, aside from being terribly stupid from a self-interested point of view, is indefensible. As Pluhar suggests, the point is rather that terms such as wanton are not and should not be employed if the killing finds justification from the resultant improvements in the well-being of higher creatures. 
nonsentient life, and that is the principle that forbids cruelty. ${ }^{10}$ Thus if there were grounds for saying that abortion as such is cruel it would be categorically impermissible. Equally, if a particular person's desire for an abortion proceeded exclusively from cruel motives or dispositions-say, to torture a fetus at an advanced stage of development after it had been removed from the womb but before it died, or simply because that person took pleasure in the thought of any suffering the fetus might undergo during abortion-that abortion would be wrong.

There are, however, no grounds for treating abortion as such as a cruel act. "Cruelty" requires that the act be done for the sake of producing pain or other suffering. There may be individuals who seek abortions out of such motives, but there is surely no evidence to support the generalization that all or any significant number of persons do so. Anyone who did so, moreover, would have to have the abortion performed in a medically improper manner since all accepted procedures employ techniques, such as the use of anesthetics, designed to eliminate pain on the part of the fetus and pain and suffering on the part of the mother. It may be true, however, that the possibility of pain increases as the fetus develops. If so, this would be one of a number of considerations in favor of having abortions performed at the earliest possible date in the pregnancy. It is also true, to reiterate, that we have identified a condition under which abortion cannot be justified.

A further albeit less demanding principle that holds for sentient creatures concerns what we might call insensitivity or indifference. In extreme forms insensitivity is difficult to distinguish from cruelty. But one can be insensitive to another creature without positively seeking to harm it or to cause it to suffer. This is a more plausible charge against those seeking abortions. They do not cruelly or maliciously seek to cause the fetus to suffer, but they are insensitive to the fact that it is impossible to achieve their objective without causing severely adverse effects for the fetus. They and those who defend them simply do not concern themselves with, do not care about, the consequences of their actions for the fetus.

This charge has a more plausible ring than that of cruelty. It takes

${ }^{10}$ It is, I think, conceptually impossible to be cruel to a creature or thing-a microbe, a plant, and so on-incapable of any kind of pain or undergoing any kind of suffering or anguish. 


\section{Toward a Liberalism}

a good part of its plausibility from the fact that a considerable number of persons view the fetus as nothing more than a bit of tissue or a blob of coagulated protoplasm and accordingly believe that no consideration whatever is owed to it. Thus we have stories, retailed by anti-abortionists, such as the tale of the couple who, despite wanting a child and fully intending to try to conceive again in a few months, sought an abortion so that a mistimed pregnancy would not interfere with a planned vacation. More generally, since abortion is the destruction of the fetus, the charge that those who seek or support the procedure are insensitive, even indifferent, to a sentient organism has an air of plausibility about it.

If more credible than the charge of cruelty, however, the allegation that abortion involves indifference or insensitivity is also wide of the mark. Those who deny that the fetus is sentient are mistaken. But if they are genuinely mistaken in their views in this regard, they cannot also be indifferent to the pain that the fetus undergoes. And for those who recognize its sentience, seeking or defending abortion may be a question not of insensitivity to the fetus but of placing higher value on the interests and desires, objectives and purposes, of the mother than on the survival of the fetus. To choose a greater good over a lesser one is not in itself to deny or to be indifferent to the lesser good. In other circumstances, not faced with such a choice, the very persons who favor abortion may well show the most exquisite sensitivity to the well-being of the fetus. Certainly it is common for women who support abortion on demand and indeed who have had abortions to take every possible care for the fetus during a desired or merely accepted pregnancy and to go out of their way in assisting others who are pregnant.

The point of these last remarks can be generalized. Criticisms that focus on alleged defects of character, motive, or disposition on the part of proponents of abortion beg the issue in question. If abortion is right or justified, it is not wrong or a defect of character to seek it or to defend it. No doubt individuals have sought and defended abortions out of bad motives and owing to serious defects of character. But one suspects that their numbers are at least matched by those who oppose abortion out of a belief that pregnant women ought to be made to carry and to rear the child as due punishment for carelessness, promiscuity, or even Eve's primeval sin against God. (A view that the fetus, if it had views, or the child that the fetus becomes, might find something less than flattering!) No amount of 
railing against either sort of person will help us to decide the merits of the issues about abortion.

Cruelty and insensitivity to the fetus, then, are as wrong as cruelty and insensitivity to any sentient creature. But the question remains whether abortion is wrong because the fetus is a sentient creature. Here again, if the value to the mother of a right to abortion is even remotely as great as I have suggested, the answer is clearly in the negative. ${ }^{11}$ Even if we put the matter in the crudest of quantitative terms, since the fetus is merely sentient, the instant of pain that it may undergo in abortion simply cannot begin to compare with the fear, the mental anguish, the frustration and derangement of life plans, that unwanted pregnancies impose on women. But of course it is wrong to put the matter this way; it is wrong to act as if human persons are as it were to be weighed on the same moral scales as merely sentient creatures.

\section{The Fetus as Possessed of Reflexive Consciousness}

Animate and sentient: those two terms exhaust the list of undoubted and undoubtedly morally relevant properties of the fetus as such. ${ }^{12}$ Because the fetus has these properties it falls under the protection of moral principles of undoubted gravity and importance. But there is simply no case at all for thinking that those protections do or should extend to the refusal of a right to abortion on demand. Any conflict between those principles and the principles

11I leave aside the fact that humans routinely destroy and cause pain to sentient creatures for reasons vastly weaker than those that support a right to abortion on demand. Many of these practices are clearly indefensible. It should nevertheless be said that if one were to start a campaign against mistreatment of sentient creatures, on any view of the matter abortion would have to take a much lower priority than those many practices that are virtually without justification.

12 Of course the fetus as such has a veritable host of other properties. Among those that figure with disturbing prominence in the anti-abortion literature:are its undeniable aesthetic properties. The fetus is commonly said to be very beautiful: delicate in features, extraordinarily intricate in its complexities, and so forth. Insofar as I can judge from photographs I have seen, I concur with these judgments. The judgments are also true of, for example, snowflakes and rock crystals. And these are reasons, albeit certainly not moral reasons, for preserving snowflakes and rock crystals under some circumstances. They are not reasons for countenancing adverse effects on human beings. Nor, incidentally, are they reasons that proabortionists should adopt for protecting the fetus. If it turned out that some or most fetuses were ugly, would we therefore be justified in destroying them? 
that celebrate and defend significant life values of human persons must be decided in favor of the latter.

It is sometimes suggested, however, that the fetus as such, at least at some stages of its development, displays some degree of complex or reflexive consciousness, not merely sentient or simple consciousness. It not only feels pain in a purely phenomenal sense that we can detect with (and indeed define in terms of readings on) scientific instruments, but it is aware of pain, may seek to avoid it, may fear it, may suffer anguish in respect to it, and so forth. If this is true, the case for thinking of the fetus as human in a moral as well as a purely genetic or biological sense would be stronger, and hence the argument that the mother should have a right to prefer her interests and desires to the survival of the fetus would be vastly more difficult to make.

The evidence proffered in support of this characterization of the fetus concerns its alleged ability to adapt to changes in its environment in ways at least analogous to the deliberate, intentional adaptations made by human persons and higher animals. Some of this evidence is purely biological or neurological. Heartbeat, brain waves, the chemical composition of blood and other bodily fluids and substances alter in response to various changes in the environment. But changes of this sort are common to all animate creatures and do not support the contention in question. ${ }^{13}$ Other evidence has at least something of a behavioral dimension and can be interpreted to indicate primitive kinds of intentionality, purposiveness, and consciousness of self. For example, the position of the fetus in the womb is known to change in response not only to chemical changes that as it were produce their own effects in it but to such influences as pressures on the womb resulting from changes in the mother's posture and related events-changes the response to which would not appear to be dictated by the changes themselves. If we can say that the fetus changes its position in the womb in something like a knowing, intentional, chosen response to such pressures, we would have at least a primitive kind of reflexive consciousness.

${ }^{13}$ Of course some of this "biological" evidence, particularly evidence concerning the central nervous system, distinguishes human fetuses from other creatures and establishes that they have the neurological potential for (the neurologically necessary conditions of) reflexive consciousness. But this evidence bears on the question of the potential immanent in the fetus, not the actuality that the fetus as such presents. I take up the question of potentiality in the following section. 
This evidence is difficult to interpret and evaluate. Part of the difficulty is due to lack of clarity in the concepts we use (and, as matters stand, must use) in interpreting it. The notion of reflexive or complex consciousness (and the idea of human personhood in the moral sense that is intimately connected with it) has a relatively straightforward and unproblematic application to the ordinary human person of, say, more than a couple years of age. In the absence of evidence of the influence of drugs, serious disease, blows on the head, and so forth, such persons present what can properly be called the paradigm of reflexive consciousness; the pattern or family of characteristics that they so abundantly and continuously display are what we mean by reflexive consciousness. But as we move away from the paradigm case, the clarity of the concept and the certainty with which we apply it slips away from us. As we consider persons who are very drowsy but not asleep, under the influence of hypnosis, drunk or otherwise drugged, temporarily amnesiac owing to an injury or severe emotional stress, suffering severe depression in the psychiatric sense, mentally defective owing to birth trauma, we are increasingly doubtful as to what to say. The same is true of movement down the ranks of the animal kingdom and, for some, of movement up the ranks of increasingly complex and adaptive machines. Because the fetus is, on any reading of the evidence, very far indeed from the paradigm case of reflexive consciousness, it is not surprising that there is controversy over how to characterize it.

There is also a special problem involved in judgments about the fetus in this regard. The problem arises from one of the elementary but also elemental facts concerning it, namely, that it is in the womb and hence can interact with those (namely, us) who must make the judgments ${ }^{14}$ only in the most narrowly circumscribed ways and for the most part only through the medium of elaborate scientific instruments (instruments that play no role in our ordinary uses of the concept of reflexive consciousness). There is a family of concepts the applicability of which makes up our notion of reflexive consciousness. "Intention," "deliberation," "choice," "reasoning," "understanding," "judgment," "having an interest" (and of course a num-

${ }^{14}$ It is hardly irrelevant to this matter that the fetus does not itself have the concept of reflexive consciousness-or any other concept-and for this among other reasons cannot tell us that it deserves this characterization. On this point, see Tooley, "Abortion and Infanticide," in Rights and Wrongs of Abortion, ed. Cohen et al. 


\section{Toward a Liberalism}

ber of more specifically moral and jural concepts to which I return below) are among the more important of these. When we can apply these concepts to a person or other creature in a positive way, we have no difficulty about characterizing that person or creature as possessed of some degree of reflexive consciousness. If, as I believe, Wittgenstein and others are correct that these concepts are built up in the course of, that their uses and their meanings take their characteristic shapes from, the interactions in which they figure and which they partly constitute, then the fact that our interactions with the fetus are so severely limited goes far to explain the difficulties we experience in trying to apply these concepts to the fetus. As Roger Wertheimer has said: "There isn't much we can do with a fetus; either we let it out or we do it in. ... As things stand, the range of interactions is so minimal that we are not compelled to regard the fetus in any particular way." 15

Because the interaction is minimal rather than nonexistent, it may be that something at least analogous to reflexive consciousness can cogently be attributed to the fetus. If so, the case against cruelty and indifference would certainly take on additional dimensions, as would the argument against utterly casual, thoughtless uses of any rights to abortion that might be established. Given that there is no evidence supporting such attributions prior to what has traditionally been called quickening, it may be that these considerations support a strong moral preference for abortions prior to that development and in any case as early as possible.

In addition to these speculations, however, there are a number of certainties concerning the alleged reflexive consciousness of the fetus as such. Prominent among these certainties are the following: none of those moral and jural attributes that we alluded to above has any application whatsoever to the fetus. A fetus cannot be generous or selfish, kind or malevolent, honest or dishonest, courageous or cowardly, just or unjust. Accordingly, a fetus cannot

${ }^{15}$ Roger Wertheimer, "Understanding the Abortion Argument," in Rights and Wrongs of Abortion, ed. Cohen et al., p. 44. A really uncompromising interpretation of Wittgenstein's discussion of logical privacy might support the conclusion that the very idea of applying the above concepts to the fetus is and must be incoherent. The conditions necessary for such an attempt to so much as get a foothold, the argument would run, are simply not satisfied. I will not try to develop such an argument here, but the possibility, which is suggested by Wertheimer's remarks as well as my own, is worth exploring. 


\section{Rights and Abortion}

deserve praise or blame, cannot be found guilty or innocent. ${ }^{16}$ Again, the fetus can be said to have needs and sensitivities and to undergo damage and pain. It is for this reason that notions such as good and bad treatment apply to it (just as they apply to all animate organisms). But not even the most expansive interpretations of the available evidence suggest that it is capable of anxiety, fear or anguish, repose, equanimity or happiness (except, of course, in the sense of "happy as a clam"). The fetus does not have hopes that can be dashed, expectations that can be disappointed, desires that can be frustrated, objectives that it can fail to attain.

These last remarks are of course no more than an elaboration on the contention that our interactions with the fetus are extremely limited. One further such elaboration may be forgiven. The fetus can be said to be a subject of our moral actions; it cannot be an agent in our moral interactions. Together with certain propositions about the logic of the concept of rights which were touched on above, it follows from these facts about it that the fetus should not be thought of as a bearer or possessor of rights. To have a right is to be in a position to choose to exercise that right or not, to waive it if one wishes, to hold others to their obligations respecting it, or to release them from those obligations. And to be a participant in the practice of rights is to be subject to the duties and obligations that correlate with the rights of others. The fetus is capable of none of these (if it is capable of any) actions. Accordingly, while the fetus is properly regarded as the subject of good and bad (including morally good and bad) treatment by human agents, it is not properly regarded as bearing, possessing, or exercising rights or of having its rights respected or violated.

It follows from the last of this set of certainties that one of the strongest possible arguments against a legal right to abortion on demand-namely, that such a right would conflict with the established and justified rights of the fetus-is without foundation. It follows from the entire set of certainties, and from our entire discussion of reflexive consciousness, that the evidence on this subject

\footnotetext{
16The constant references to the innocence of the fetus, to abortion as the taking of innocent life, are of course misplaced. Aside, perhaps, from contexts involving religious doctrines concerning original sin, the concept of innocence has no more application to the fetus than the concept of guilt. (And of course in the Christian religious doctrine, if the fetus is a human being it is guilty, not innocent.)
} 


\section{Toward a Liberalism}

adds very little to the arguments against abortion which are based on the undeniable fact that the fetus is animate and sentient. In particular, there is virtually no basis for the claim that the fetus as such is a human person in a moral as well as a biological sense or that it should be protected by those moral principles that apply distinctively to creatures who are human in the moral sense.

Arguments Grounded in the Potential Carried by (Immanent in) the Fetus as Such

Abortions do not destroy human persons. Abortions destroy fetuses. Of course we know that the fetus will, with due care on the part of human persons (and a little luck), almost certainly become a human person. This fact does not warrant us in saying that a fetus is a human person. The fact that a bowl of batter will, with due care (and a great deal of luck) become a gorgeous and delectable soufflé does not transmute the bowl of batter into a soufflé. A soufflé is one thing, a bowl of soufflé batter is another. A fetus is one thing, a human person is another. No amount of emphasis on the indeed wonderful genetic and other biological properties of the fetus can change this.

Still, we treat the bowl of soufflé batter differently from, say, a dustpan of dirt swept up from the kitchen floor. Since the bowl of batter is not notably admirable or useful as such, our doing so makes no sense apart from what the bowl of batter can become. If we admire and enjoy soufflés, we can hardly be altogether contemptuous of or: indifferent to the batches of batter from which they rise so majestically. If we assign great value to human persons, we can hardly altogether withhold value from the fetuses from which human persons develop. Thus the question is not whether to assign value to the fetus but what sort of value to assign to it and how to assess that value when serving and respecting it conflicts with the value we accord to human persons and the quality of lives they are able to lead.

Before taking up the latter question-which is of course the crucial one under this heading and perhaps in the whole issue about abortion-there are two associated questions that require discussion. The questions concern the "slide" down one or another of the "slippery slopes" that are said to descend precipitously from the 
plateau of safe argumentative ground that both pro- and antiabortionists seek to attain and hold.

Many contemporary anti-abortionists want to defend the fetus but to allow the use of contraceptives (and perhaps masturbation, so-called unnatural sexual acts, and so forth). Most pro-abortionists want to allow destruction of the fetus but to disallow infanticide (and the killing of other creatures who are human in the biological sense but who are said not to be human persons in the full moral sense of the term). Pro-abortionists regularly contend that antiabortionists cannot rationally or nonarbitrarily stop the "slide" or "regress" to positions that they themselves reject. If it is the fetus's potential to become a human person that requires a prohibition against abortion, and if that same potential is immanent in any spermatozoon or ovum, then should there not also be a prohibition against the use of contraceptives, against masturbation to climax, against "wasting" the fluids by ejaculating them into various "inappropriate" orifices? Indeed if human beings have the capacity to produce ova and spermatozoa, should they not be prohibited from any actions or practices that may damage, destroy, or fail to utilize that capacity? If poor dietary habits, the use of alcohol, tobacco, marijuana or other drugs, excessive work, too little sleep, and so forth produce sterility, impotence, or frigidity, should they not be banned? Should vows of chastity and the beliefs and teachings that promote them not be forbidden? With comparable gusto anti-abortionists contend that there is no rational barrier to the "slide" or "progress" of the pro-abortion position to defense of a right to destroy any and all creatures who are like the fetus in lacking those attributes that define a human person in the full moral sense. If it is true that the cortical development necessary to full reflexive consciousness is not complete until approximately the infant's first birthday, is infanticide not every bit as defensible as feticide? If the development of full personality is prevented or arrested due to disease, accident, or other untoward events, should not those who are burdened by the life of the unfortunate victim of such events have a right to take that life?

It is not surprising that both sides have had difficulty in dealing with these questions and meeting these objections. The anti-abortionist can hardly resist the move from arguments grounded exclusively in the characteristics of the fetus as such to arguments relying 
on what it will become. But from the moment that move has been made the argument has to contend with the fact that the fetus represents (among other things) one moment or stage in a continuous biological process that can be, in the wider sense of the word, aborted at any moment or stage. If it is the culmination of that process that matters, one interruption in it can be made to appear as indefensible as any other. The pro-abortionist is faced with a comparable difficulty. As we have seen, concepts such as "human person," "moral personality," "reflexive consciousness," "capacity for distinctively human interaction" apply over a range or continuum of cases that is by no means precisely delineated. They are, in Wittgenstein's fashionable phrase, family resemblance concepts for the proper use of which it is impossible to state necessary and sufficient conditions. Moreover, many if not all of the characteristics over which their applications range are themselves fluid and developmental, not static or fixed. The moral personality of a twoyear-old child is a vastly different thing than that of an adult.

Recognizing that, and why, both positions face such closely analogous difficulties ought to persuade us to a certain humility in discussing these matters. The game of trading charges in this regard is an amusement in which it is easy enough to score points; but the high scores that result aren't likely to signal progress in resolving issues about abortion.

For what it is worth, I am inclined to allow that there is a valid and morally significant distinction between conception (or perhaps implantation) and everything that precedes it. The union of a spermatozoon and an ovum (or that union plus segmentation and implantation) produces a new entity with characteristics not possessed by its causal antecedents in the biological process, characteristics deserving of at least the kinds of moral consideration discussed above. Abortion is a more serious matter than the use of contraceptives. But the distinction between a fetus and an infant is at least as clear and at least as morally significant. This is true from the outset (that is, from parturition), and the clarity and moral significance of the distinction are heightened and enhanced very rapidly from the instant of birth forward. From that instant the infant displays a repertoire of behaviors (crying, gurgling, sucking, eye and other facial and bodily movements) which are either impossible in the womb or impossible for us to perceive and interact with when occurring in the womb. Items in that repertoire, as well as the 


\section{Rights and Abortion}

remarkable responses they commonly evoke in the human persons about the infant, multiply in number and increase in complexity in ways that are not only extraordinary (except that they are entirely ordinary!) but that could not occur if the creature remained a fetus. Given these facts, and given that our moral conceptions and relationships concern the experiences we in fact have and the interactions in which we in fact engage (if only vicariously), it would be astonishing if the fetus-infant distinction ceased to be accorded substantial moral significance. The infant is not a human person in the full sense; there are significant distinctions between the infant and the child, the child and the adolescent, and so forth. (One of these is that, in my view, the infant and the youngish child should not be thought of as bearers of rights.) But this does not alter the fact that there is a clear and morally significant distinction between the fetus and the infant.

But should that distinction be accorded the degree of significance necessary to justify a legal right to abortion on demand? If there were no substantial, no weighty considerations in favor of such a right, the answer to this question would be no. If sexual relations, pregnancy, childbirth, and child rearing were biologically, economically, socially, emotionally, and above all morally trivial, inconsequential, and easily accommodated, the fact that the fetus is biologically human and is very likely to become a human person if not aborted would be enough to justify narrow limitations on abortion. But of course the conditional just mentioned is wildly counterfactual. Sexual relations, childbearing and rearing, especially for women, are manifestly among the weightiest, the most consequential and demanding, of life's experiences. Because this is so, it is difficult to think of any very large number of actions that are prima facie more eligible for the protection of a legal right (liberty) than the act of having an abortion.

Against the argument for such a right stands the potential for human interaction, human personhood and personality, that is immanent in the fetus. A particular instantiation of that potential is destroyed every time an abortion is performed. This is no insignificant consideration. But there is a material difference between potentiality and actuality. The millions of women whose day-to-day lives are so heavily affected by the availability (or not) of a legal right to abortion are not to be thought of in the subjunctive or the future tense. Their interests and desires, their objectives and purposes, and 


\section{Toward a Liberalism}

the joy and delight, the pain and the anguish that they experience in pursuing their objectives are real and material, vivid and intense. It is in no small part because the human person that the fetus becomes will have such experiences that we ought to value its potential. It is dubious in the extreme to claim that we place immense, even absolute value on what the fetus will become at the same time that we go on sacrificing vital aspects of the well-being of those who now are what the fetus may someday be. If sensitivities even comparable to those sometimes lavished on the potential carried by the fetus are allowed in respect to the actuality presented by women, the case for a right to abortion on demand would be very strong. But such "evenhandedness" would be altogether misplaced. Beyond those characteristics of the fetus as such that were discussed above, the fetus is a bundle of human potential. But the woman who may want (now or sometime) but cannot have an abortion is a thinking, judging, feeling, hoping, believing human person who suffers in a here and now that may last much of her life. ${ }^{17}$

To deny a legal right (liberty) to abortion is knowingly to condemn very large numbers of actual human persons to pain and anguish and severely to restrict the freedom and quality of life of many more. We must accord this preeminently moral feature of the situation the serious consideration it obviously deserves. If we do so, the uncertain protection ${ }^{18}$ that prohibiting abortions provides

17For an extreme case of this sort of "impartiality," see Baruch A. Brody, "Abortion and the Sanctity of Human Life," American Philosophical Quarterly Io (April I973):I33ff. Brody argues that a fetus may be aborted to save the life of the mother only if the following conditions are satisfied: (I) in the absence of an abortion both the mother and the fetus will die "relatively soon"; (2) the decision to abort the fetus (rather than let the mother die and save the fetus) is made by a fair-that is, presumably a random-procedure. In short, in Brody's view there is no morally relevant difference between the mother and the fetus. For the full range of Brody's views on this subject, see his book Abortion and the Sanctity of Human Life (Cambridge: MIT l?ress, 1975).

${ }^{18}$ Although I have chosen not to emphasize the kind of consideration alluded to in the text, it is worth noting that at least some of the adverse effects of prohibiting abortion fall with virtual certainty on women, while the benefits, to the fetus, of the prohibition are uncertain at best.

Having allowed questions of a probabilistic sort into the discussion to this extent, it should also be mentioned that questions about abortion would be substantially complicated if in fact so few women wanted to bear children that a right to abortion actually threatened the continued existence of the human race. Because this is not the case, I will take up these complexities only to the extent of saying that it is less than obvious that denial of the right would be the morally appropriate response to 
the fetus will not stand against the argument for a right to abortion on demand. ${ }^{19}$

The major (secular) arguments against a legal right (liberty) to abortion on demand have now been considered. Before concluding this part of the discussion, however, two related but in some respects distinct objections must be considered.

First, there is the objection that according a right to abortion will have psychological or cultural (that is, causal) consequences going beyond the effects of abortion itself. Specifically, it will produce a generalized weakening in respect for and the resolve to protect life and it will lead to the acceptance of infanticide, euthanasia, and other forms of killing. To my knowledge this objection, as commonly encountered as it now is, has not been formulated with the precision necessary to a determination of whether the empirical evidence that its cogency presupposes is in fact available. Nor has that evidence been produced.

For present purposes the more important consideration is that establishing the truth of the empirical propositions on which the objection depends would not itself constitute a conclusive argument against a legal right to abortion on demand. If a right to abortion is

such a development. It is not self-evident that the fact that women have the biological capacity to conceive and bear children justifies treating them and their lives as resources implicitly available for this or any other project.

${ }^{19}$ The important reflections of Judith Jarvis Thomson and Mary Anne Warren should be mentioned at this point. Thomson calls our attention to how seldom any of us are legally or morally required to make sacrifices even remotely comparable to those involved in unwanted pregnancy, child rearing, and the fear thereof. See her "A Defense of Abortion," in Rights and Wrongs of Abortion, ed. Cohen et al. Warren presents an analogy that helps to focus thought on the sacrifices we would be willing to make or impose on behalf of potential such as the fetus carries. She asks us to imagine (I have entered some minor modifications in her analogy) that our bodies could be split up into parts with each part (like so many plant cuttings) capable of becoming or generating a human person. If so, we would be presented with a choice between keeping our bodies whole and thereby wasting the immense human potential they carry or splitting them up so as to let that potential be realized. Perhaps some truly heroic persons would be willing to sacrifice their lives so as to utilize their capacity in this regard to the full; perhaps some number of others would be willing to give up an arm, a leg, some flesh from an inconspicuous part of their body, and so forth. Would there be any justification of requiring anyone to do any of these things; for punishing them or holding them morally blameworthy if they refused? See Mary Anne Warren, "The Moral and Legal Status of Abortion," Monist 52 (1973):42ff. For a related analogy, see Tooley, "Abortion and Infanticide," in Rights and Wrongs of Abortion, ed. Cohen et al. 


\section{Toward a Liberalism}

justified, and if the alleged causal consequences of according that right are objectionable, it would be open to us to accord the right and to take independent steps to prevent the objectionable consequences from ensuing. The most important of such steps would be to show that, and why, infanticide, euthanasia, or whatever kind of killing we wish to oppose is distinct from abortion such that the latter is justified and the former is not and to try to get others to accept that judgment. Doing this much would presumably help to block the objectionable consequences. It would also put us in a position to defend whatever legal prohibitions against other forms of killing prove to be necessary to our objective. ${ }^{20}$

The second objection (or group of connected objections) relates to concessions that I have made to anti-abortion arguments. I have

${ }^{20}$ Owing to the reliance my argument for abortion makes on reflexive consciousness and moral interaction, a word must be said about kinds of killing, in addition to abortion, that would appear to be justified by that argument. I refer in particular to cases in which a human person ceases to display reflexive consciousness and ceases to be an agent in (as opposed to a subject of) moral interactions. If the loss is known (that is, known with the greatest certainty medical science allows) to be permanent, the case for a right to take the life of the erstwhile person seems to me to be at least as strong as the case for a right to abortion. It is, in fact, clearly stronger in one obvious respect; namely, that the organism in question does not possess the potential carried by the fetus. Such cases, however, are seriously complicated (as against the case of abortion) by two factors, the first of sometimes wrenching practical difficulty but of no great theoretical significance, the second of both practical and theoretical significance. The first is that it is often difficult to determine who should have the right to terminate the life of the organism. In the case of the fetus the mother's interests are sufficiently clear and paramount to make this decision unproblematic in most cases. But when tragedy befalls mature persons the matter is often anything but clear. The second complication arises from the fact that, unlike the fetus, such organisms have histories as persons in the full moral sense. These are largely histories of interactions with others who continue to be persons, interactions that will of course have produced attitudes, beliefs, emotional ties, and so forth that do not simply cease at the moment the interactions cease.

This second consideration is not a reason against a right to terminate the life of an organism that was once a person. It is a reason to expect that exercising such a right will be an agonizing, wrenching experience for those who must decide whether to do so and to expect that the latter will in fact often make great sacrifices rather than take the life. (Just: as the fact that mothers, at least those not taught to look on the fetus as some kind of punishment inflicted upon them, can easily imagine a personal history for the fetus explains that they so often make the extraordinary sacrifices that the bearing and rearing of children entail.)

For present purposes, however, the importance of the second consideration is that it provides the necessary distinction between the fetus and persons who have temporarily lost reflexive consciousness and the capacity for moral agency and 
agreed that the fetus has moral value and standing and found that certain ways of treating it are morally wrong. If so, the objection runs, will not a legal right (liberty) to abortion on demand encourage, indeed license, wrongful treatment of the fetus?

There are actually several objections lurking here. The first is essentially the same as the objection just rejected. And the answer to it is the same. If certain ways of treating the fetus are known to be wrong, indeed if the argument for abortion itself includes a demonstration that they are wrong, then a right to abortion could be shown to "encourage" the wrongful treatments only by establishing contingent causal connections that have not in fact been established and that in any case would not be decisive against a right to abortion. Nor could such a right be said to "license" the wrongful treatments in the sense of explicitly and positively providing a warrant for them.

It might be argued, however, and this is the second of this second set of objections, that a legal liberty does license wrongful treatments of the fetus in the sense that it withdraws legal protection from it and leaves the question of how it will be treated to the discretion of private persons. But the assumption on which this objection rests is false. To accord a legal right to abortion on demand no more withdraws all legal protection from the fetus than does according a right to kill animals for human consumption withdraw such protections for animals as, for example, are provided by laws against cruelty to them. If cruelty or insensitivity were features of abortion itself, this argument would be cogent. Because they are not, the argument fails.

The third and last of this set of objections is that the right itself will be abused and that abuses will be difficult or impossible to prevent. People will seek and will obtain abortions for reasons as bad as or worse than those of the avid vacation seekers mentioned earlier. I don't suppose anyone knows, or knows how to find out or predict, exactly how often this sort of thing has occurred or will occur. Most rights are sometimes abused in the sense that people

interaction. Unlike the fetus, they do not merely have the potential to develop these characteristics, they have a history of such characteristics. And because they have such a history, they have a relationship to other moral agents that no fetus as such can ever have. For an opposing position, see Eike-Henner Kluge, The Practice of Death (New Haven: Yale University Press, 1975), chap. I. 


\section{Toward a Liberalism}

put them to uses distant from and even antithetical to the interests and objectives in terms of which the rights are usually justified. Think of the abuses of the right to private property-for example, the ways in which wealthy property owners hold the disadvantaged to the strict letter of their obligations in respect to those rights. Think of the abuses that have been made of rights such as freedom of speech, press, and association by individuals seeking to destroy such rights altogether. Where the argument for the value of these rights has continued to command widespread allegiance, the recurrence of such abuses has not been viewed as a sufficient reason for disestablishing the rights themselves.

There are, however, conceptual issues of some importance here, one of which points ahead to questions about moral rights in the sense of liberties and both legal and moral rights in the strict sense. The first point takes us back to the logic distinctive of a right. Rights are conclusive against some range of known or anticipated objections. In the case of a legal right (liberty), the right is conclusive against all legal objections to the action protected by the right. Now, one could attempt to define the legal right to having an abortion in such a way as to exclude from the actions protected by it abortions sought for indefensible reasons. In the same way, one could define the rights of contract so as to exclude from them, say, the right of a wealthy person or a bank to foreclose on a mortgage held against a poor person unable to meet the mortgage payments. This would be to preserve the stringency or conclusiveness of the warrant the right provides but to restrict the range of objections against which it is in fact conclusive.

But there is another kind of move available, one that is preferable in this kind of case. It is well established that it can be morally wrong to do something that one has a legal right to do. No legal action can be taken or brought against the person who exercises the right in a morally wrongful manner, but that person is nevertheless subject to certain kinds of criticism and disapproval. For reasons that I will take up in the next section, this seems to me to be the best way of handling the kind of abuse of the legal right (liberty) to abortion on demand that I am now discussing.

The case for a legal right (liberty) to abortion on demand deserves acceptance. The considerations in favor of this right are firmly grounded in deep and vital human interests and purposes, interests and purposes that themselves arise out of some of the most continu- 
ing and morally salient dimensions of the lives of human persons. The arguments against the right are sufficient to establish that the fetus should be accorded moral value and standing of a kind that any moral person will respect and seek to protect. They are not sufficient to disjustify the right. The fetus is an animate and barely more than sentient creature with the potential to become a human person. It would be wrong to prefer preservation of instances of it to the service of profound and pervasive concerns of actual human persons.

\section{Can a Moral Right (Liberty) to Abortion on Demand Be Justified?}

Some arguments for a legal right (liberty) to abortion on demand rely heavily on distinctive characteristics of legal prohibitions or requirements such as that they are enforced by the coercive power of the state. Given the widespread and cogently argued disagreement over abortion, for both normative and prudential reasons the state ought to withdraw and let the issue be resolved by the moral rather than the legal community. ${ }^{21}$

Although not without their merits, I have not relied on such arguments here. Rather, I have contended that the moral case for abortion on demand is very strong and that it deserves the positive support that is accorded by giving it the standing of a right. (If this argument were widely rejected, I might fall back to the "weaker" position that abortion ought to be "decriminalized." But that would be a tactical retreat.) For this reason, my argument for a legal right (liberty) is also an argument for a moral right (liberty) to that action. There ought to be such a moral right.

Accordingly, the only distinct issue to be taken up under the present heading concerns the implications, for the $B$ 's, of $A$ having a moral right (liberty) as well as a legal right (liberty) to abortion on demand. In the latter case the implication is that $B$ cannot properly act to make abortion legally wrong, and cannot attempt to punish $A$ for having an abortion or punish any other person for giving $A$ an abortion that $A$ desires. In the former case, $B$ cannot properly

21See, for example, Wertheimer, "Understanding the Abortion Argument," in Rights and Wrongs of Abortion, ed. Cohen et al., the final paragraphs. 


\section{Toward a Liberalism}

contend that it is morally wrong for $A$ to have an abortion and cannot bring moral criticism to bear on $A$ for doing so. Thus far the implications are entirely parallel. But there is at least one important difference between the two cases. In the law, any given abortion either is or is not legally wrong. That is the only judgment that the law as such can make. But morality and moral judgment commonly allow of differentiations that are more subtle and refined than are ordinarily possible in the law. The $B$ 's might accept the position that there is a right to abortion and accept the implication that they should therefore ordinarily refrain from criticizing $A$ 's for seeking or having one. Consistent with this position, however, they might hold out the possibility of making and expressing a number of kinds of judgments about conditions ancillary to or associated with the seeking and having of abortions. To our vacationists, for example, they might say: "We recognize and respect your right to abortion on demand and we will interfere in this case only to the extent of saying that we think your reasons for wanting this abortion are vile and repugnant." Persons who said this kind of thing about any very wide array of reasons for having an abortion would probably demonstrate by doing so that they did not in fact accept that right. It is nevertheless a valuable feature of moral as opposed to legal rights that genuine acceptance of and respect for them is compatible with recognizing and forcefully recording one's objections to their abuse. Thus a moral right (liberty) to abortion on demand is valuable both for the protections it accords the $A$ 's and for the flexibility of response that it makes available to $B$ 's who respect $A$ 's right.

\section{Can a Legal or Moral Right in the Strict Sense to Abortion on Demand Be Justified?}

As noted earlier, it is a feature of the concept of a right in the strict sense that such rights impose some definite and affirmative obligation or obligations on some identifiable B's. The concept itself, however, tells us no more than this. Specifically, it tells us nothing about the incidence or the content of those obligations in respect to any particular right. ${ }^{22}$ Thus there could be a legal or a moral right in

22In fact, the obligations are sometimes specified in the rules that establish the right; sometimes they must be inferred from the characteristics of the right itself and what would be destructive of or perhaps necessary to its successful exercise. 
the strict sense that imposed obligations on doctors or other qualified medical personnel, on hospitals and clinics, on the state, on insurance companies, and the like. And the obligations could be to perform or to see to or to pay for the performance of abortions; to do so unqualifiedly on demand, only in the first trimester or under other conditions; to provide postabortion care and counseling; and so forth through a considerable list of possibilities.

Because I cannot begin to deal with this array of possibilities, I restrict myself, by way of concluding this chapter, primarily to comments on the possible obligations of medical or paramedical personnel qualified to perform abortions. Given that some persons in this category hold strongly felt moral objections against abortion, can we say that the right to abortion on demand includes the right to demand that persons competent to perform an abortion actually do so? Specifically, does a woman have a right to demand an abortion from a medically competent (and otherwise available) individual who personally believes that abortion is morally wrong? Is the argument for a right to abortion on demand strong enough to justify the imposition of such an obligation on persons who do not find that argument convincing? (Note that the question also arises in somewhat less dramatic ways in respect to persons other than those who actually perform the operation. It arises in regard to nurses and many others who must assist more or less directly with the procedure. And in jurisdictions in which the government has undertaken to provide or to assist with the costs of abortion it arises in some degree in respect to all citizens or subjects.)

The answer to these questions is a qualified yes. It is yes because (I) the argument for abortion on demand is very strong and (2) because, as things stand, a woman cannot safely (or even surely) abort herself. Owing to (I), we can say that the views of those who contend that abortion is morally indefensible are not well grounded. Having considered the arguments for this position and found them wanting, we cannot turn about and say that they nevertheless provide adequate support for the position they defend. Owing to (2) we can say that the right to abortion on demand could be, as a practical matter, a nullity if abortions could not in fact be obtained from those competent to perform them. Thus if it were the case that the demand for abortions were too great to be met by those both competent and willing to perform them, there would be adequate justification for establishing either a legal or a moral right (or both) in the strict sense 


\section{Toward a Liberalism}

that imposed (on those medically competent to do so) an obligation to provide abortions. (There is also adequate justification for using public funds to pay for abortions for persons-in jurisdictions with free enterprise medical practice-who cannot afford them.)

The yes is qualified for the same kinds of reasons that have convinced a number of societies to qualify the obligations imposed on pacifists and other conscientious objectors to do military service in what are believed to be justified wars. It is not that their arguments are judged to be convincing. If that were the case, others would have to give up their position in favor of the position of the pacifists. But where the position of the pacifist or other objecting position is believed by others to be cogent and sincerely held, and where it is believed that the justified objectives can be achieved while conceding something to the views of the objectors, an effort is made to find ways of making such concessions. Conditions of this kind have not always been satisfied in respect to abortion. But because they do seem to be satisfied at the present time, it would be morally insensitive (it would be a violation of LP) not to accommodate to the views of those who object to abortion insofar as we can. Thus we should establish both a legal and a moral right in the strict sense to abortion on demand. And so far as we can do so without nullifying the right, we should excuse from the correlative obligations those persons for whom abortion remains morally unacceptable.

\section{Conclusion}

The concept of a right is one of the most widely used, and most commonly abused, items in our moral and political lexicon. We hear claims to an extraordinary variety of rights and we find rights attributed to an astonishing diversity of creatures and things. Although this proliferation represents a kind of tribute to the not inconsiderable success of a comparatively recent legal and moral innovation of genuine value, there is reason to view the proliferation with skepticism. We may be experiencing a kind of inflationary spiral that will end by unnecessarily diminishing the real and distinctive goods that can be obtained with this part of our conceptual currency.

This concern, however, does not properly extend to the campaign 
for a right to abortion on demand. In adopting the language of rights, pro-abortionists have made precisely the correct conceptual choice. As I have tried to show, "a right" provides the conceptualization, and hence the moral and jural attribute, exactly appropriate to the case that the pro-abortionist wants to make. For this reason, because that case is very strong, and because its strength derives in no small part from the support it receives from the principle (LP) which provides the optimum basis for defending individual rights, a right to abortion on demand is exactly what women ought to have. 